\title{
Comparable Sustained Virologic Suppression Between Community- and Academic-based HIV Care Settings
}

\author{
Carolyn Chu, MD, MSc, Moonseong Heo, PhD, Alex Peshansky, MS, Galina Umanski, MS, \\ Paul Meissner, MSPH, Cindy Voss, MA, and Peter A. Selwyn MD, MPH
}

Purpose: The human immunodeficiency virus (HIV)/acquired immunodeficiency syndrome epidemic in the United States is evolving because of factors such as aging and geographic diffusion. Provider shortages are also driving the restructuring of HIV care delivery away from specialized settings, and family medicine providers may play a larger role in the future. We attempted to compare the effectiveness of HIV treatment delivered at community versus hospital care settings.

Methods: The outcome of interest was sustained virologic suppression defined as 2 consecutive HIV-1 RNA measurements $\leq \mathbf{4 0 0}$ copies/mL within 1 year after antiretroviral initiation. We used data from the multistate HIV Research Network cohort to compare sustained virologic suppression outcomes among 15,047 HIV-infected adults followed from 2000 to 2008 at 5 community- and 8 academic hospitalbased ambulatory care sites. Community-based sites were mostly staffed by family medicine and general internal medicine physicians with HIV expertise, whereas hospital sites were primarily staffed by infectious disease subspecialists. Multivariate mixed effects logistic regression controlling for potential confounding variables was applied to account for clustering effects of study sites.

Results: In an unadjusted analysis the rate of sustained virologic suppression was significantly higher among subjects treated in community-based care settings: 1,646 of $2,314(71.1 \%)$ versus 8,416 of $12,733(66.1 \%)(P<.01)$. In the adjusted multivariate model with potential confounding variables, the rate was higher, although not statistically significant, in the community-based settings (adjusted odds ratio, 1.26; 95\% confidence interval, $0.73-2.16$ ).

Conclusion: Antiretroviral therapy can be delivered effectively through community-based treatment settings. This finding is potentially important for new program development, shifting HIV care into community-based settings as the landscape of accountable care, health reform, and HIV funding and resources evolves. (J Am Board Fam Med 2015;28:72-81.)

Keywords: HIV, Primary Health Care

The US health care system is struggling with new human immunodeficiency virus (HIV) infections and a diminishing HIV workforce. ${ }^{1,2}$ These are occurring in the face of efforts to initiate early

This article was externally peer reviewed.

Submitted 21 March 2014; revised 17 July 2014; accepted 22 July 2014.

From the Department of Family and Social Medicine, Montefiore Medical Center/Albert Einstein College of Medicine, Bronx NY (CC, GU, PM, PAS); the Department of Epidemiology and Population Health, Albert Einstein College of Medicine, Bronx NY (MH); the Harold and Muriel Block Institute for Clinical and Translational Research at Einstein and Montefiore, Albert Einstein College of Medicine, Bronx NY (AP); and the HIV Research Network, Johns Hopkins University School of Medicine, Baltimore, MD (CV).

Funding: The HIV Research Network is supported by the Agency for Health care Research and Quality (290-010012). This study was also supported in part by the Einstein- treatment for improved individual and public health outcomes. ${ }^{3-5}$ Community-based and family medicine providers are increasingly called on to deliver HIV care, ${ }^{6,7}$ and novel programs (eg, the

Montefiore Institute for Clinical and Translational Research (UL1 RR025750) and the Einstein-Montefiore Center for AIDS Research (P30AI051519).

Conflict of interest: none declared.

Disclaimer: The Agency for Health care Research and Quality (AHRQ) is not responsible for the design and conduct of the study; collection, management, analysis, interpretation of the data; or preparation, review, or approval of the manuscript. The views expressed in this article are those of the authors. No official endorsement by the AHRQ is intended or should be inferred.

Corresponding author: Moonseong Heo, PhD, Department of Epidemiology and Population Health, Albert Einstein College of Medicine, 1300 Morris Park Ave, Bronx, NY 14061 (E-mail: moonseong.heo@einstein.yu.edu). 
Health Resources and Services Administration's "Expanding HIV Training into Graduate Medical Education" initiative) are attempting to expand education and address health disparities. ${ }^{8-11}$ The Health Resources and Services Administration reported that community health centers provided care to 94,605 HIV-positive patients in 2011, a $4.4 \%$ increase from $2010 .{ }^{12}$ In addition, major efforts to better engage and retain people living with HIV (PLWH) in care, such as timely diagnosis and use of community-based settings, are underway. ${ }^{13-15}$

Preliminary studies suggest community-based ambulatory care of PLWH may be comparable to hospital-based ambulatory care. ${ }^{16,17}$ These are important findings given the changing epidemiology of HIV/acquired immunodeficiency syndrome (AIDS), the increasing longevity of PLWH, and multifactorial chronic diseases that contribute to rapidly evolving health care needs. HIV providers are also at risk for "provider burnout," 18 and many longtime HIV providers are expected to retire soon, leaving a significant workforce shortage., ${ }^{2,19}$ HIV treatment in the United States_often based in academic hospitals and centralized around specialized resources-is likely to become integrated into community and primary care health centers, similar to what is done in areas with fewer resources. ${ }^{20-23}$ This can help ensure that the broader needs of an enlarging population are adequately met.

The objectives of the present study were to (1) describe HIV-infected adults followed at academic hospital-based versus community ambulatory care centers participating in a large consortium of HIV care sites, the HIV Research Network (HIVRN) ${ }^{24}$; and (2) compare the effectiveness of 1-year antiretroviral outcomes between the 2 care settings after controlling for potential confounding variables.

\section{Methods}

\section{HIVRN Study Sites and Research Subjects}

The HIVRN currently consists of 18 sites (Appendix 1) that provide ambulatory HIV services to adults and children. All HIVRN sites are staffed by HIV experts and see a high volume of HIV-infected patients, ranging from $\sim 350$ to $\geq 5000$ patients per site. ${ }^{25}$ Each site's participation in the HIVRN is approved by their respective institutional review board. Data collected for HIVRN include demographic, clinical, treatment, labora- tory, service usage, and vital status information. Data elements are abstracted yearly from medical charts at each site via standardized protocols, deidentified, and submitted to HIVRN's Data Coordinating Center. All participating sites are required to submit the same elements.

\section{Community versus Hospital Setting}

Community-based sites were community-oriented health centers or integrated health care systems whose primary purpose was to serve residents of the surrounding communities. Hospital sites were mainly academically oriented "teaching" hospitals or hospital systems, although many provided care to residents of the surrounding communities. Hospital sites were typically located within or adjacent to academic hospitals. All hospital-based sites were affiliated with an academic medical center, whereas only 1 community-based site had an academic affiliation. Study authors were blinded to specific location of care.

\section{Antiretroviral Therapy}

For the large majority of this study's review period, 3 main classes of antiretroviral therapy (ART) were used: (1) nucleoside/nucleotide reverse transcriptase inhibitors (NRTIs); (2) non-nucleoside reverse transcriptase inhibitors (NNRTIs); and (3) protease inhibitors (PIs). Newer classes of agents, such as entry inhibitors and integrase inhibitors, were approved for use in the late 2000s; until recently, they were generally only used in patients who exhibited treatment failure when receiving the more widely used, "first-line" agents. Combination ART was defined as a regimen with more than 2 drugs that included a PI, NNRTI, entry inhibitor, and/or other cornerstone drug; a regimen was identified as new if it was the start of therapy overall or if there was a change in the cornerstone drug.

\section{Provider Characteristics}

Both hospital- and community-based sites were staffed primarily by attending physicians, including infectious disease subspecialists, internal medicine providers with HIV expertise, and family medicine providers with HIV expertise. Specifically, community-based sites were staffed mostly by family medicine providers with HIV expertise and general internists with HIV expertise, although a few had infectious disease subspecialists on staff. In contrast, hospital-based sites were staffed primarily by 
infectious disease subspecialists. Midlevel providers such as physician assistants and nurse practitioners also provided direct patient care in the 2 settings, if not at every site. Attending physicians and midlevel providers had similar panel sizes ( $>100$ patients) and patient volume per half-day clinic session. The range of experience was comparable across the sites, from $<5$ to $>15$ years. More details are provided elsewhere. ${ }^{25}$

\section{Main Outcome Measure}

The main outcome for the present study was sustained virologic suppression, defined as achievement of 2 consecutive plasma HIV-1 RNA viral load (VL) measurements $\leq 400$ copies $/ \mathrm{mL}$ within 1 year after starting any new combination ART regimen (see Appendix 2 for how incomplete VL measurements were handled). Some subjects were receiving multiple regimens during the review period; however, each subject was counted only once as either a treatment success, that is, achievement of sustained virologic suppression as defined above, or a treatment failure. Subjects who achieved sustained virologic suppression on a particular regimen after previous failures were ultimately counted as a treatment success. Subjects receiving multiple regimens who never achieved sustained virologic suppression were counted as failures. In addition, because subjects had VL measured within the scope of routine care-rather than at preset times, as with controlled trials-we examined values up to 14 months after ART initiation. There were no minimum or maximum criteria for time elapsed between the 2 consecutive VLs of $\leq 400$ copies/mL, as long as both occurred within 14 months after initiating ART.

\section{Inclusion/Exclusion Criteria}

In this study subjects were HIV-infected adults $\geq 18$ years old who initiated combination ART (cART) while enrolled in care any time between January 1, 2000, and December 31, 2008. Subjects were included if they had at least 1 outpatient medical visit and 1 Cluster of Differentiation 4 (CD4) measurement per year while enrolled in care and if they started a new combination ART regimen for any duration during the review period. Subjects who started cART in 2008 were included if their laboratory data after December 31, 2008, were available for evaluation. Subjects were excluded if they had no CD4 or VL measurements available before the ART start date or after the regimen start date; these subjects were identified as "lost to follow-up." Subjects were also excluded if VL was $\leq 400$ copies/mL before ART. Finally, subjects were excluded if there were fewer than $2 \mathrm{VL}$ measurements during the 12 months after ART initiation. Subjects who died during the study period also were excluded.

\section{Included Sites and Subjects}

Fifteen sites treating adult patients were initially included; these sites had complete data available through 2008. Ten sites were hospital-based and 5 were community-based ambulatory care sites. Across these 15 sites, a total of 42,523 subjects were followed by the HIVRN during the period of 2000 to 2008; among this overall cohort, 9473 subjects were not receiving ART or cART, leaving 33,050 (77.8\%) subjects receiving cART. Of this population, 5 exclusionary conditions were accounted for: 1140 died; 2035 had actually started cART before the review period and were therefore ineligible for our outcome evaluation; 5256 did not have at least $1 \mathrm{CD} 4$ and VL measurement available before and after the ART start date; 5436 subjects has VL $\leq 400$ copies $/ \mathrm{mL}$ before treatment; and $4236 \mathrm{had}$ missing or fewer than $2 \mathrm{VL}$ measurements available during the review period after ART initiation. Figure 1 stratifies these numbers by care setting.

After applying the inclusion/exclusion criteria, all subjects from 2 of the original hospital sites were excluded, which resulted in a total of 15,047 subjects from the remaining 13 sites ( 8 hospital and 5 community sites) for the present study analysis. Specifically, the 15,047 subjects had definite ART treatment outcomes- either sustained VL suppression or treatment failure; $12,733(84.6 \%)$ were seen in academic hospital-based clinics and 2314 $(15.4 \%)$ were seen in community-based clinics.

\section{Predictor Variable}

The predictor variable was the dummy-coded setting of HIV care: community-based or academic hospital-based care setting.

\section{Covariates of Interest}

Age at baseline, sex, self-reported race/ethnicity, HIV risk factor(s), CD4 before ART, VL before ART, ART regimen type, and number of outpatient medical visits during the review period (per subject) were evaluated for the multivariate model. HIV risk factor was coded as heterosexual trans- 
Figure 1. Flow chart showing selection of HIV Research Network (HIVRN) subjects eligible for analyses and final outcome measurement. cART, combination antiretroviral therapy; VL, viral load.

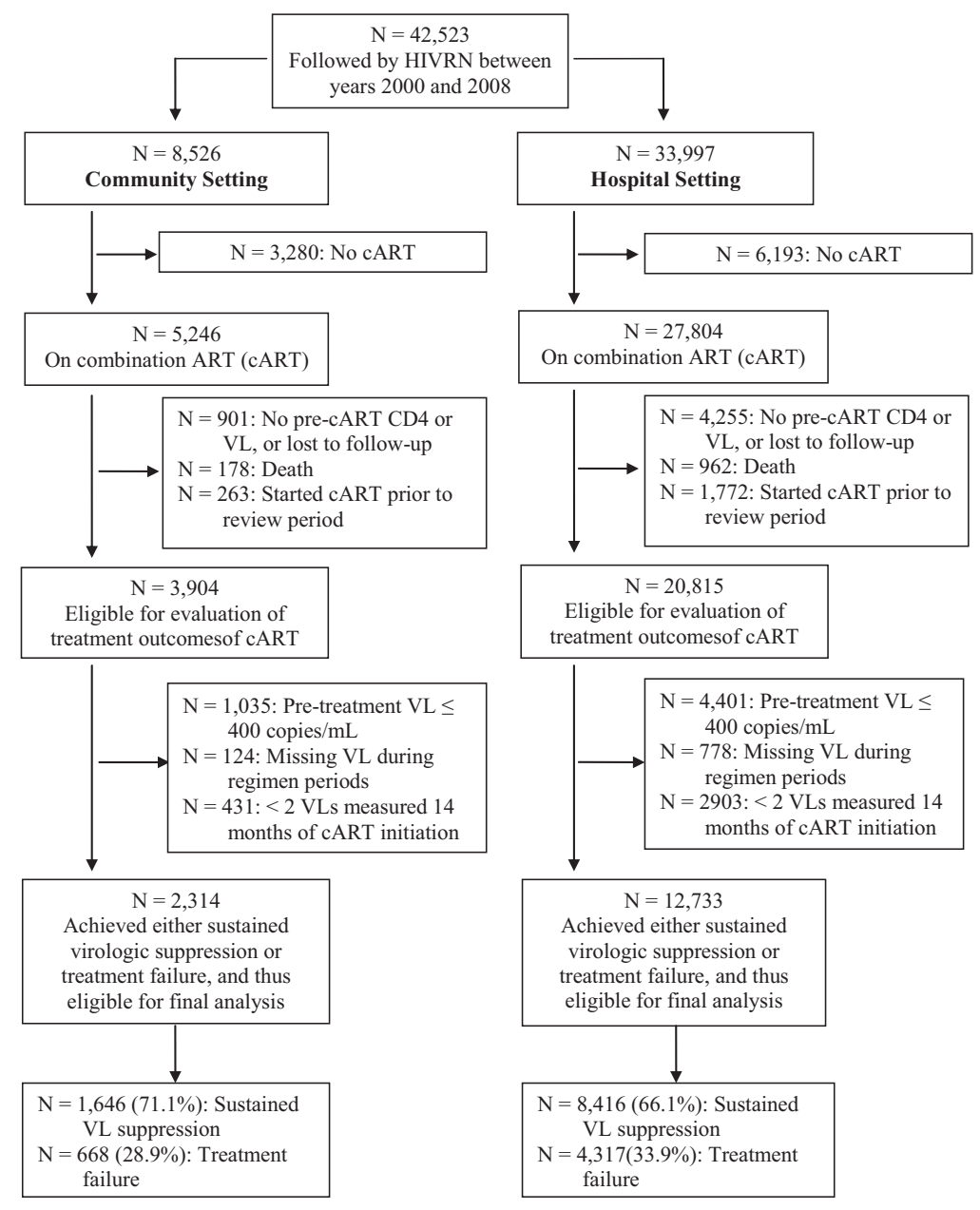

mission; men who have sex with men; injection drug use (IDU), which included IDU in conjunction with other risk factors; or "other," which included unknown risk behavior. Except for subjects with IDU, these risk behaviors were treated as mutually exclusive. Initial CD4 was defined as the first CD4 measurement during the review period. Both CD4 and VL before ART were defined as the most recent CD4 and VL measurements preceding (or on) a regimen start date, respectively. CD4 increase was defined as the difference between CD4 before ART and the maximum CD4 attained after initiating a regimen.

\section{Statistical Analysis}

For descriptive statistics, we used percentages, means, and standard deviations stratified by the 2 care settings. Categorical data on demographic and clinical characteristics were compared using $\chi^{2}$

tests; continuous data were compared using the Student $t$ test or Wilcoxon rank-sum test, as appropriate. A generalized linear mixed effects logistic model was applied to test the treatment outcomes between the 2 settings; the hospital setting was considered the referent setting. This model takes into account within-site binary outcome correlations for statistical inference by including sites as a random effect. We conducted bivariate analysis comparing success rates of sustained virologic suppression between the care settings using a $\chi^{2}$ test. This analysis was followed by multivariate analysis to account for nonrandomized patient allocation, variability in provider/practice type, and differences in subject characteristics, including potential confounding variables that differed significantly between the 2 settings: age at baseline, sex, race/ ethnicity, HIV risk factor, CD4 before ART, $\log _{10}$ VL before ART, number of outpatient visits during 
review period, and regimen type. Differences were considered statistically significant at $\alpha=0.05$; reported confidence intervals (CIs) are 2-sided. Statistical analysis was conducted using SAS software version 9.13 (SAS Institute, Cary, NC). Specifically, we applied the SAS GLIMMIX macro for the fit of the generalized linear mixed effects logistic model.

\section{Results}

\section{Subject Cbaracteristics}

Table 1 compares demographic, clinical, and health care utilization characteristics for subjects between care settings. There seemed to be no clinically meaningful differences in age between care settings. Initial mean CD4 also did not differ significantly $\left(272\right.$ cells $/ \mathrm{mm}^{3}$ for community subjects vs 277 cells $/ \mathrm{mm}^{3}$ for hospital subjects). However, mean CD4 before ART was significantly higher (266 vs 238 cells $/ \mathrm{mm}^{3} ; P<.01$ ) and mean $\log _{10} \mathrm{VL}$ before ART was significantly lower (4.3 vs $4.5 ; P<$ .01) among community subjects.

\section{Treatment Characteristics}

PI-based regimens were started more frequently overall $(53 \%)$ than NNRTI-based combinations

Table 1. Subjects Initiating Combination Antiretroviral Therapy in Community- and Hospital-Based Ambulatory Care Settings Within the HIV Research Network from 2000 to 2008

\begin{tabular}{|c|c|c|c|}
\hline Characteristics & $\begin{array}{l}\text { Community-Based Care } \\
(\mathrm{n}=2314)\end{array}$ & $\begin{array}{l}\text { Hospital-Based Care } \\
\quad(\mathrm{n}=12,733)\end{array}$ & $P$ Value* \\
\hline Age (years), mean (SD) & $38.5(9.2)$ & $38.1(9.1)$ & $<.05$ \\
\hline Male sex & $1685(72.8)$ & $9215(72.4)$ & NS \\
\hline \multicolumn{4}{|l|}{ Race/ethnicity } \\
\hline White & $828(35.8)$ & $3459(27.2)$ & \multirow[t]{4}{*}{$<.01$} \\
\hline African American/Caribbean & $1028(44.4)$ & $6270(49.2)$ & \\
\hline Hispanic & $386(16.7)$ & $2727(21.4)$ & \\
\hline Other & $72(3.1)$ & $277(2.2)$ & \\
\hline \multicolumn{4}{|l|}{ HIV risk factor } \\
\hline Heterosexual transmission & $995(43.0)$ & $4487(35.2)$ & \multirow[t]{4}{*}{$<.01$} \\
\hline MSM & $975(42.1)$ & $5094(40.0)$ & \\
\hline IDU & $288(12.4)$ & $2589(20.3)$ & \\
\hline Other & $37(1.6)$ & $197(1.5)$ & \\
\hline Initial CD4 during review period (cells $\left./ \mathrm{mm}^{3}\right)$, mean (SD) & $272(238)$ & $277(240)$ & NS \\
\hline CD4 before ART (cells $/ \mathrm{mm}^{3}$ ), mean (SD) & $266(237)$ & $238(201)$ & $<.01$ \\
\hline $\log _{10}$ viral load before treatment viral load, mean (SD) & $4.3(0.9)$ & $4.5(0.9)$ & $<.01$ \\
\hline Number of outpatient visits per subject over review period, mean (SD) & $35.4(32.4)$ & $32.8(26.6)$ & NS \\
\hline \multicolumn{4}{|l|}{ Type of ART initiated } \\
\hline PI only regimen & $1200(51.9)$ & $6758(53.1)$ & \multirow[t]{5}{*}{$<.01$} \\
\hline NNRTI only regimen & $724(31.3)$ & $3713(29.2)$ & \\
\hline PI and NNRTI & $139(6.0)$ & $1038(8.2)$ & \\
\hline NRTI only & $146(6.3)$ & $844(6.6)$ & \\
\hline Other $^{\dagger}$ & $105(4.5)$ & $380(3.0)$ & \\
\hline Number of days on ART (index regimen ${ }^{\ddagger}$ ), mean (SD) & $632.7(524.0)$ & $538.6(473.2)$ & $<.01$ \\
\hline Achieved sustained virologic suppression & $1646(71.1)$ & $8416(66.1)$ & $<.01$ \\
\hline CD4 increase (cells $\left./ \mathrm{mm}^{3}\right)$, mean (SD) & $215(220)$ & $197(208)$ & $<.01$ \\
\hline
\end{tabular}

Data are $\mathrm{n}(\%)$ unless otherwise indicated.

${ }^{*} P$ values based on Student $t$ test, Wilcoxon rank-sum test, or Pearson $\chi^{2}$.

${ }^{\dagger}$ Regimens that included at least one non-PI/NNRTI antiretroviral medication were labeled "other," regardless of whether a PI/NNRTI was concurrently prescribed as part of that regimen combination.

${ }^{\text {I}}$ Index regimen refers to the regimen that contributed to either sustained virologic suppression or treatment failure; for subjects with multiple occurrences of either outcome, the earliest qualifying regimen was counted as the index regimen. Treatment start and stop dates were submitted by HIVRN study sites.

ART, antiretroviral therapy; CD4, Cluster of Differentiation 4; IDU, intravenous drug use; MSM, men who have sex with men; NNRTI, non-nucleoside reverse transcriptase inhibitor; NRTI, nucleoside/nucleotide reverse transcriptase inhibitor; NS, not significant; PI, protease inhibitor; SD, standard deviation. 
$(30 \%)$ in both academic hospital- and communitybased settings and at relatively similar frequencies between the 2 care settings. Only 7\% of ARTtreated subjects in both settings started regimens containing both a PI and an NNRTI, and even fewer (4\%) started regimens containing other cornerstone agents (such as integrase and entry inhibitors). Mean duration of ART for hospital-based subjects was significantly shorter compared with that of community-based subjects (539 vs 633 days; $P<$ $.01)$. Mean CD4 increase was also significantly smaller for hospital-based subjects compared with that of community-based subjects (197 vs 215 cells/ $\left.\mathrm{mm}^{3} ; P<.01\right)$.

\section{Outcome Comparisons Between Settings}

Bivariate analysis revealed that subjects in community-based settings achieved a higher rate of sustained virologic suppression compared with those in the academic hospital-based settings (Table 1): 1,646 of $2,314(71.1 \%)$ versus 8,416 of 12,733 (66.1\%) $(P<.01)$, respectively, a statistically significant difference. Furthermore, the multivariate analysis (Table 2) revealed that sustained virologic suppression among community-based subjects was more likely, if not statistically significantly more likely, than among hospital-based patients (adjusted odds ratio [OR], 1.26; 95\% CI, 0.73-2.17).

Finally, the OR of sustained virologic suppression was higher with higher age and higher CD4 before ART but lower with higher VL before ART; lower VL before treatment is a known predictor of virologic suppression and time to suppression. There were also statistically significant variations in the odds of sustained virologic suppression by race/ ethnicity, HIV risk factor(s), and regimen type. Specifically, subjects who initiated NNRTI-based regimens and regimens based on other classes had significantly higher odds of achieving sustained virologic suppression compared with subjects who initiated PI-based regimens; adjusted ORs for these groups were 1.47 (95\% CI, 1.35-1.60) and 2.79 (95\% CI, 2.15-3.63), respectively.

\section{Discussion}

This study is one of the largest we are aware of comparing virologic outcomes for HIV-infected patients starting combination ART in communityversus academic hospital-based ambulatory care settings across the United States. Our results indi-
Table 2. Multivariable-Adjusted Estimates of Sustained Virologic Suppression Among Adults Initiating Combination Antiretroviral Therapy in the HIV Research Network from 2000 to 2008

\begin{tabular}{|c|c|c|}
\hline Variables & $\begin{array}{c}\text { Adjusted } \mathrm{OR}^{*} \text { for } \\
\text { Sustained Virologic } \\
\text { Suppression }(95 \% \mathrm{CI})\end{array}$ & $\begin{array}{c}P \\
\text { Value }\end{array}$ \\
\hline \multicolumn{3}{|l|}{ Setting } \\
\hline $\begin{array}{l}\text { Hospital-based ambulatory } \\
\text { care }\end{array}$ & Reference & - \\
\hline $\begin{array}{l}\text { Community-based } \\
\text { ambulatory care }\end{array}$ & $1.26(0.73-2.17)$ & NS \\
\hline \multicolumn{3}{|l|}{ Age (years) } \\
\hline$\geq 50$ & Reference & - \\
\hline $40-49$ & $0.82(0.72-0.93)$ & $<.01$ \\
\hline $30-39$ & $0.70(0.62-0.80)$ & $<.01$ \\
\hline $18-29$ & $0.65(0.56-0.75)$ & $<.01$ \\
\hline \multicolumn{3}{|l|}{ Sex } \\
\hline Male & Reference & - \\
\hline Female & $1.08(0.98-1.19)$ & NS \\
\hline \multicolumn{3}{|l|}{ Race/ethnicity } \\
\hline White & Reference & - \\
\hline African American/Caribbean & $0.85(0.77-0.94)$ & $<.01$ \\
\hline Hispanic & $1.18(1.05-1.33)$ & $<.01$ \\
\hline Other & $1.31(0.99-1.73)$ & NS \\
\hline \multicolumn{3}{|l|}{ HIV risk factor } \\
\hline Heterosexual transmission & Reference & - \\
\hline MSM & $1.14(1.03-1.27)$ & $<.01$ \\
\hline IDU & $0.82(0.74-0.91)$ & $<.01$ \\
\hline Other & $0.91(0.67-1.22)$ & NS \\
\hline \multicolumn{3}{|l|}{ CD4 before ART $\left(\right.$ cells $\left./ \mathrm{mm}^{3}\right)$} \\
\hline$<50$ & Reference & - \\
\hline $50-199$ & $1.16(1.05-1.29)$ & $<.01$ \\
\hline $200-349$ & $1.40(1.26-1.57)$ & $<.01$ \\
\hline $350-499$ & $1.44(1.25-1.65)$ & $<.01$ \\
\hline$\geq 500$ & $1.27(1.09-1.47)$ & $<.01$ \\
\hline $\log _{10}$ viral load before ART & $0.76(0.73-0.80)$ & $<.01$ \\
\hline \multicolumn{3}{|l|}{$\begin{array}{l}\text { Outpatient visits during review } \\
\text { period (n) }\end{array}$} \\
\hline$\geq 4$ & Reference & - \\
\hline$<4$ & $0.78(0.57-1.08)$ & NS \\
\hline \multicolumn{3}{|l|}{ Type of ART } \\
\hline PI only regimen & Reference & - \\
\hline NNRTI only regimen & $1.47(1.35-1.60)$ & $<.01$ \\
\hline NNRTI and PI & $0.73(0.64-0.83)$ & $<.01$ \\
\hline NRTI & $0.78(0.68-0.90)$ & $<.01$ \\
\hline Other & $2.79(2.15-3.63)$ & $<.01$ \\
\hline
\end{tabular}

*Multivariate odds ratios include adjustment for care setting, age, sex, race/ethnicity, HIV risk factor, CD4 before antiretroviral therapy (ART), $\log _{10}$ viral load before ART, number of outpatient visits during the review period, and ART regimen type.

ART, antiretroviral therapy; CD4, Cluster of Differentiation 4; CI, confidence interval; IDU, intravenous drug use; MSM, men who have sex with men; NNRTI, non-nucleoside reverse transcriptase inhibitor; NRTI, nucleoside/nucleotide reverse transcriptase inhibitor; NS, not significant; OR, odds ratio; PI, protease inhibitor. 
cate that among the HIVRN's multisite cohort, community-based subjects had favorable odds of sustained virologic suppression within 1 year compared with hospital-based subjects. These results build on other studies describing treatment outcomes in community-based and primary care settings. ${ }^{16,17,26}$ Using data from urban cohorts, other researchers have demonstrated that patients followed by primary care/community-based clinicians achieved relatively high rates of virologic suppression $(\sim 60-70 \%)$, similar to specialty/hospitalbased clinics.

Virologic suppression rates among our subjects (71\% for community-based and $66 \%$ for hospitalbased) are also comparable to those reported from Ryan White-funded grantees during the same time frame: 2007 HIVQual-US data indicate $57.6 \%$ of patients on ART maintained viral suppression, with an average clinic rate of $56.2 \%$ (the lowest- and highest-performing $10 \%$ of clinics reported rates of $\leq 33.3 \%$ and $\geq 75.0 \%$, respectively). ${ }^{27}$ The slightly higher rates at HIVRN-affiliated centers (regardless of setting) may be attributed, at least in part, to high levels of provider expertise. These sites may also have access to resources such as adherence counselors, case managers, and/or pharmacy medication management programs. ${ }^{28}$

Some of our findings may have special implications for health service delivery. The overall values for initial CD4 and CD4 before ART were alarmingly low for all subjects across both settings-well below recommended levels for ART initiation. ${ }^{29}$ This underscores the importance of early HIV diagnosis and successful linkage-to-care programs so that timely treatment can be initiated. Communityand primary care-based settings that offer convenient (ie, co-located) access to HIV treatment soon after diagnosis can potentially help increase the numbers of patients engaged in timely care. Furthermore, only 1 of the 5 HIVRN communitybased sites is affiliated with an academic medical center, whereas all the hospital-based sites are; this suggests that an academic affiliation may not be necessary to deliver high-quality HIV care. Antiretroviral management is arguably the most sophisticated skill maintained by HIV providers and the least easily "systematized"; therefore it is paramount that appropriately trained providers are integrated into all HIV treatment settings to ensure delivery of high-quality care.
We noted that CD4 before ART was lower for hospital- versus community-based subjects (238 vs 266 cells $/ \mathrm{mm}^{3}$ ) despite similar initial CD4 counts. This difference is likely explained by higher VL before treatment among hospital-based subjects and/or unmeasured variables such as active substance use or mental health disorders interfering with treatment initiation, rather than a difference in care quality ${ }^{30}$; nevertheless, the difference in $\log _{10} \mathrm{VL}$ (4.3 vs 4.5 ) before treatment between the 2 settings may not be clinically meaningful, even if it is statistically significant. In addition, many patients attending hospital-based settings may have been referred from inpatient units where they exhibited complications of advanced HIV disease or from providers who had reached the limits of their expertise and were uncomfortable managing patients with complex resistance profiles. Though not statistically significant, the overall adjusted OR of virologic suppression favoring community-based sites possibly reflects differences in patient disease severity (as evidenced by CD4 and VL values before treatment) rather than structural differences between the 2 settings; examination of the variance components revealed that between-clinic variation $(14 \%)$ was smaller than within-clinic variation (86\%), suggesting that the outcome variation was more attributable to individual subjects than care settings.

With regard to the types of ART initiated in the 2 settings, there did not seem to be major meaningful differences. Slightly more subjects initiated PI-based combinations in both groups-an unsurprising finding since more than $98 \%$ of subjects had experience with antiretrovirals (possibly because a sizeable portion had failed first-line, typically NNRTI-based regimens). Our finding that NNRTI-only regimens had higher sustained suppression (adjusted OR, 1.47) compared with PIonly regimens may be because of the improved adherence with NNRTI-based regimens through decreased pill burden and/or fewer side effects. Since we did not examine specific antiretroviral combinations, however, we cannot make any definitive conclusions about the comparative use of specific regimens in the 2 settings. Finally, the mean length of time on ART was significantly shorter for hospital-based subjects (632.7 vs 538.6 days), which possibly reflects treatment discontinuation by hospital providers because of poor medication adherence and/or identification of treatment resistance. 
Further examination is necessary to clarify factors driving these findings, and potential future work involves detailed evaluation of the use of second-/ third-line, etc., combinations and antiretroviral resistance management by providers in different settings. Examining other patient/disease-oriented outcomes for patients followed in these settings (eg, long-term virologic, immunologic, and/or clinical outcomes) may also be worthwhile.

There are some limitations to this study. First, only 5 community-based sites contributed data; our findings should therefore be viewed as somewhat provisional pending a larger sample of communitybased HIV treatment centers. HIVRN's community-based sites may not be completely representative of all community-based HIV care because they are located in urban areas, staffed by HIV experts, and see a large volume of HIV-infected patients. Our findings may not generalize to solo or smallgroup practices or treatment programs in rural locations where the model of HIV management may differ from that at the HIVRN sites. Another limitation is that this study involved a secondary data analysis, and some potentially relevant variables (eg, antiretroviral adherence) were not captured. Finally, a large portion of subjects were excluded $(27,476$ of 42,523 , or $65 \%)$; however, analysis of the characteristics of the excluded subjects is beyond the scope of this study and may deserve a separate independent study. As with any study, if unmeasured variables contributed to bias or limited the generalizability of this work, our findings should be interpreted cautiously.

Strengths of this work include both the large size of the population and the nature of the subjects. The HIVRN involves a well-studied, multisite cohort that represents a unique group of large-volume, community-based HIV practices, the likes of which will probably increase as HIV care becomes less centralized because of difficulties maintaining hospital/specialty-based practices, particularly because of financial and/or workforce limitations in some areas.

\section{Conclusion}

This work supports the potential value of communitybased HIV care by demonstrating that 1-year ART treatment outcomes do not significantly differ between subjects starting ART in community-based versus hospital-based settings. The epidemiology of HIV/AIDS in the United States is rapidly evolv- ing because of several factors, including patient aging, development of chronic comorbidities, and geographic diffusion. ${ }^{31}$ Provider shortages are also driving the restructuring of HIV services, and many believe HIV ought to be decentralized, or "mainstreamed" into community/primary careoriented health centers. For example, only $\sim 10 \%$ of community health centers receive funding through Part C of the Ryan White HIV/AIDS Program. Such restructuring is well aligned with National HIV/AIDS Strategy goals, namely, reducing health disparities and addressing the increasingly complex health care needs of an enlarging HIV-infected population. Our findings have potentially important implications for new policy initiatives to stimulate program development, including the shift of HIV treatment into community-based settings.

CC, MH, and PM conceived of and designed the study. CC and $\mathrm{MH}$ drafted the manuscript and jointly supervised all aspects of the study. $\mathrm{CC}$ and $\mathrm{CV}$ acquired the data. $\mathrm{CC}, \mathrm{MH}, \mathrm{AP}$, and $\mathrm{GU}$ managed data and conducted statistical analysis. $\mathrm{CC}, \mathrm{MH}$, and PAS interpreted the results.

\section{References}

1. Stevens LC, Webb AA, Davis S, Corless I, Portillo C. HIV care provider shortages highlighted in national meeting. J Assoc Nurses AIDS Care 2008;19: 412-4.

2. Adams J, Chacko K, Guiton G, Aagaard E. Training internal medicine residents in outpatient HIV care: a survey of program directors. J Gen Intern Med 2010; 25:977-81.

3. Valdiserri RO, Holtgrave DR, West GR. Promoting early HIV diagnosis and entry into care. AIDS. 1999; 13:2317-30.

4. Fleishman JA, Yehia BR, Moore RD, Gebo KA, Network HIVR. The economic burden of late entry into med care for patients with $\mathrm{HIV}$ infection. Med Care 2010;48:1071-9.

5. Health HIV Research. The state of HIV primary care: a shifting landscape. January 27, 2012. Available from: http://www.healthhiv.org/modules/info/files/ files_4f280446b0c51.pdf. Accessed February 1, 2012.

6. Korthuis PT, Berkenblit GV, Sullivan LE, et al. General internists' beliefs, behaviors, and perceived barriers to routine HIV screening in primary care. AIDS Educ Prev 2011;23:70-83.

7. Bradford JB, Coleman S, Cunningham W. HIV system navigation: an emerging model to improve HIV care access. Aids Patient Care STDS 2007;21(Suppl 1):S49-58.

8. Fleishman JA, Yehia BR, Moore RD, Gebo KA, Agwu AL. Disparities in receipt of antiretroviral 
therapy among HIV-infected adults (2002-2008). Med Care 2012;50:419-27.

9. Koester KA, Maiorana A, Vernon K, Myers J, Rose CD, Morin S. Implementation of HIV prevention interventions with people living with HIV/AIDS in clinical settings: challenges and lessons learned. AIDS Behav 2007;11(5 Suppl):S17-29.

10. The White House Office of National AIDS Policy. National HIV/AIDS strategy for the United States. July 2010. Available from: http://www.whitehouse. gov/sites/default/files/uploads/NHAS.pdf. Accessed December 17, 2013.

11. HRSA Newsroom. HRSA awards \$5.1 million to bolster HIV/AIDS training and technical assistance programs. Rockville (MD): Health Resources and Services Administration; 2011. Available from: http://www. hrsa.gov/about/news/pressreleases/110907hivtraining. html. Accessed December 18, 2012.

12. Valdiserri R. Celebrating community health centers. blog.AIDS.gov; August 10, 2012. Available from: http://blog.aids.gov/2012/08/celebrating-communityhealth-centers.html. Accessed December 16, 2013.

13. Horstmann E, Brown J, Islam F, Buck J, Agins BD. Retaining $\mathrm{HIV}$-infected patients in care: where are we? Where do we go from here? Clin Infect Dis 2010;50:752-61.

14. Thompson MA, Mugavero MJ, Amico KR, et al. Guidelines for improving entry into and retention in care and antiretroviral adherence for persons with HIV: evidence-based recommendations from an International Association of Physicians in AIDS Care Panel. Ann Intern Med 2012;156:817-33, W-283-94.

15. Health Resources and Services Administration and HIV AIDS Bureau. Outreach: engaging people in HIV care. Summary of a HRSA/HAB 2005 consultation on linking PLWH into care. August 2006. Available from: http://hab.hrsa.gov/abouthab/files/ hivoutreachaug06.pdf. Accessed December 12, 2013.

16. Rastegar DA, Fingerhood MI, Jasinski DR. Highly active antiretroviral therapy outcomes in a primary care clinic. AIDS Care 2003;15:231-7.

17. Chu C, Umanski G, Blank A, Grossberg R, Selwyn PA. HIV-infected patients and treatment outcomes: an equivalence study of community-located, primary care-based HIV treatment vs. hospital-based specialty care in the Bronx, New York. Aids Care 2010; 22:1522-9.

18. Kerr ZY, Miller KR, Galos D, Love R, Poole C. Challenges, coping strategies, and recommendations related to the HIV services field in the HAART era: a systematic literature review of qualitative studies from the United States and Canada. AIDS Patient Care STDS 2013;27:85-95.

19. Carmichael JK, Deckard DT, Feinberg J, et al; the AAHIVM and HIVMA Medical Workforce Working Group. Averting a crisis in HIV care: a joint statement of the American Academy of HIV Medicine (AAHIVM) and the HIV Medicine As- sociation (HIVMA) on the HIV medical workforce. June 2009. Available from: http://www. idsociety.org/uploadedFiles/IDSA/Policy_and_Advocacy/ Current_Topics_and_Issues/Workforce_and_Training/ Statements/AAHIVM\%20HIVMA\%20Workforce\%20 Statement\%20062509.pdf. Accessed December 12, 2013.

20. Boulle A, Van Cutsem G, Hilderbrand K, et al. Seven-year experience of a primary care antiretroviral treatment programme in Khayelitsha, South Africa. AIDS 2010;24:563-72.

21. Cohen R, Lynch S, Bygrave H, et al. Antiretroviral treatment outcomes from a nurse-driven, communitysupported HIV/AIDS treatment programme in rural Lesotho: observational cohort assessment at two years. J Int AIDS Soc 2009;12:8.

22. Kredo T, Ford N, Adeniyi FB, Garner P. Decentralising HIV treatment in lower- and middle-income countries. Cochrane Database Syst Rev 2013;6: CD009987.

23. Rich ML, Miller AC, Niyigena P, et al. Excellent clinical outcomes and high retention in care among adults in a community-based HIV treatment program in rural Rwanda. J Acquir Immune Defic Syndr 2012;59:e35-42.

24. HIV Research Network. Hospital and outpatient health services utilization among HIV-infected patients in care in 1999. J Acquir Immune Defic Syndr 2002;30:21-6.

25. Yehia BR, Gebo KA, Hicks PB, et al. Structures of care in the clinics of the HIV Research Network. Aids Patient Care STDS 2008;22:1007-13.

26. Fingerhood M, Rastegar DA, Jasinski D. Five-year outcomes of a cohort of HIV-infected injection drug users in a primary care practice. J Addict Dis 2006; 25:33-8.

27. New York State Department of Health AIDS Institute, US Health Resources Services Administration (HRSA) HIV/AIDS Bureau. HIVQUAL-US Annual Data Report: based on 2007 performance data. Available from: http://www.nationalqualitycenter.org/index. cfm/5913/14067. Accessed November 20, 2014.

28. de Bruin M, Hospers HJ, van Breukelen GJP, Kok G, Koevoets WM, Prins JM. Electronic monitoringbased counseling to enhance adherence among HIVinfected patients: a randomized controlled trial. Health Psychol 2010;29:421-8.

29. HHS Panel on Antiretroviral Guidelines for Adults and Adolescents. Guidelines for the use of antiretroviral agents in HIV-1-infected adults and adolescents. 2013. Available from: http://www.aidsinfo. nih.gov/contentfiles/lvguidelines/adultandadolescentgl. pdf. Accessed December 12, 2013.

30. Merlin JS, Westfall AO, Raper JL, et al. Pain, mood, and substance abuse in HIV: implications for clinic visit utilization, antiretroviral therapy adherence, and virologic failure. J Acquir Immune Defic Syndr 2012;61:164-70. 
31. Chu C, Umanski G, Blank A, Meissner P, Grossberg R, Selwyn PA. Comorbidity-related treatment outcomes among $\mathrm{HIV}$-infected adults in the Bronx, NY. J Urban Health 2011;88:507-16.

\section{Appendix 1}

Institutions Participating in the HIVRN (Contributing HIVRN Principal Investigators by Site) and Sponsoring Agencies

Alameda County Medical Center, Oakland, CA (Howard Edelstein, MD)

Children's Hospital of Philadelphia, Philadelphia, PA (Richard Rutstein, MD)

Community Health Network, Rochester, NY (Roberto Corales, DO)

Drexel University, Philadelphia, PA (Jeffrey Jacobson, MD; Sara Allen, CRNP)

Fenway Health, Boston, MA (Stephen Boswell, MD)

Johns Hopkins University, Baltimore, MD (Kelly Gebo, MD; Richard Moore, MD; Allison Agwu, MD)

Montefiore Medical Group, Bronx, NY (Robert Beil, MD)

Montefiore Medical Center, Bronx, NY (Lawrence Hanau, MD)

Oregon Health and Science University, Portland, OR (P. Todd Korthuis, MD)

Parkland Health and Hospital System, Dallas, TX (Ank Nijhawan, MD; Muhammad Akbar, MD)

St. Jude's Children's Hospital and University of Tennessee, Memphis, TN (Aditya Gaur, MD)

St. Luke's Roosevelt Hospital Center, New York, NY (Victoria Sharp, MD; Stephen Arpadi, MD)

Tampa General Health Care, Tampa, FL (Chararut Somboonwit, MD)

University of California, San Diego, CA (W. Christopher Mathews, MD)

Wayne State University, Detroit, MI (Jonathan Cohn, MD)
Note: Three institutions have two sites treating adults and children separately.

\section{Sponsoring Agencies}

Agency for Healthcare Research and Quality, Rockville, MD (Fred Hellinger, PhD; John Fleishman, $\mathrm{PhD}$; Irene Fraser, $\mathrm{PhD}$ )

Health Resources and Services Administration, Rockville, MD (Robert Mills, PhD; Faye Malitz, MS)

Data Coordinating Center

Johns Hopkins University (Richard Moore, MD; Jeanne Keruly, CRNP; Kelly Gebo, MD; Cindy Voss, MA)

\section{Appendix 2}

\section{Handling Incomplete HIV-1 RNA VL Measurements}

Because of HIVRN's multisite and longitudinal nature, multiple HIV-1 RNA assays were used across sites. Many VL measurements were recorded as " $<n$ " rather than a discrete value (the original database contained 23 unique $n$ 's, ranging from 0 to $5,000,000$ copies $/ \mathrm{mL}$ ). We converted measurements recorded as " $<n$ " to the value of $n$ itself if $n$ was $\leq 400$ copies $/ \mathrm{mL}$. Measurements recorded as " $<n$ " where $n$ was $>400$ copies $/ \mathrm{mL}$ were treated as missing because such a record could not definitively be attributed to a particular reason such as data entry error. Similarly, measurements recorded as " $>n$ " were converted to $n$ if $n$ was $>400$ copies $/ \mathrm{mL}$ and treated as missing if $n$ was $\leq 400$ copies $/ \mathrm{mL}$. The number of measurements recoded as missing totaled only 192 of 547,108 originally recorded measurements $(<0.1 \%)$. In addition, if a subject had more than $1 \mathrm{VL}$ measurement recorded on the same date, the maximum value was used to maintain a conservative estimate for sustained virologic suppression. This occurred for $2361 \mathrm{mea}-$ surements, representing $<1 \%$ of the originally recorded values. 